\title{
Characterization of proliferating cell nuclear antigen (PCNA) from pathogenic yeast Candida albicans and its functional analyses in S. Cerevisiae
}

Kodavati Manohar and Narottam Acharya*

\begin{abstract}
Background: Proliferating cell nuclear antigen (PCNA/POL30) an essential protein forms a homotrimeric ring encircling dsDNA and serves as a molecular scaffold to recruit various factors during DNA replication, repair and recombination. According to Candida Genome Database (CGD), orf19.4616 sequence is predicted to encode C. albicans PCNA (CaPCNA) that has not been characterized yet.

Results: Molecular modeling studies of orf19.4616 using S. cerevisiae PCNA sequence (SCPCNA) as a template, and its subsequent biochemical characterizations suggest that like other eukaryotic PCNAs, orf19.4616 encodes for a conventional homotrimeric sliding clamp. Further we showed by surface plasmon resonance that CaPCNA physically interacted with yeast DNA polymerase eta. Plasmid segregation in genomic knock out yeast strains showed that CaPCNA but not its G178S mutant complemented for cell survival. Unexpectedly, heterologous expression of CaPCNA in S. cerevisiae exhibited slow growth phenotypes, sensitivity to cold and elevated temperatures; and showed enhanced sensitivity to hydroxyurea and various DNA damaging agents in comparison to strain bearing SCPCNA. Interestingly, wild type strains of C. albicans showed remarkable tolerance to DNA damaging agents when compared with similarly treated yeast cells.

Conclusions: Despite structural and physiochemical similarities; we have demonstrated that there are distinct functional differences between SCPCNA and CaPCNA, and probably the ways both the strains maintain their genomic stability. We propose that the growth of pathogenic $C$. albicans which is evolved to tolerate DNA damages could be controlled effectively by targeting this unique fungal PCNA.
\end{abstract}

Keywords: Sliding clamp, Native PAGE, Complementation, Hydroxyurea, DNA damage tolerance, Surface plasmon resonance

\section{Background}

Proliferating cellular nuclear antigen (PCNA), an evolutionarily conserved protein found in eukaryotes and archaebacteria serves as a docking platform for many proteins that function in DNA replication, repair, recombination, cell cycle, and chromatin remodeling $[1,2]$. It belongs to a family of sliding clamps that increase processivity of replicative DNA polymerases [3, 4]. Despite little sequence similarity among the sliding clamps in all

\footnotetext{
* Correspondence: narottam_acharya@ils.res.in

Laboratory of Genomic Instability and Diseases, Department of Infectious Disease Biology, Institute of Life Sciences, Bhubaneswar 751023, India
}

domains of life, they possess superimposable threedimensional structures with highly conserved functions [1]. A typical sliding clamp comprises of multimeric, toroidal-shaped structures with pseudo-six fold symmetry that encircles the DNA double helix $[5,6]$. While $\beta$-clamp, the sliding clamp of eubacteria is a homodimer; PCNA of eukaryotes and T4 bacteriophage is a homotrimer, and a heterotrimer in archaea $[7,8]$. Each PCNA monomer consists of two globular topologically identical domains connected by an inter domain connecting loop (IDCL). The three dimensional structure reveals that the inner surface of the PCNA ring is comprised of $12 \alpha$-helices 
with suitably exposed positively charged amino acids to interact with the sugar-phosphate backbone of DNA, whereas the outer surface is composed of 54 $\beta$-sheets and three IDCLs appropriate for protein-protein interactions $[5,6]$. PCNA by itself cannot directly encircle DNA; rather it is loaded by a eukaryotic clamp loader, RFC [9]. The loaded PCNA ring only recruits polymerases and other factors firmly to DNA, making the sliding clamp an essential cofactor for DNA transaction processes. Apart from DNA polymerases, PCNA is found to interact with proteins such as FEN1, DNA glycosylases, DNA ligase I, p21, CCK2, cyclin D, DNA methyltransferases etc. [2, 10-16]. PCNA interacts with its partners mostly through its IDCL but occasionally by its C-terminus, the center loop and the backside loop [17] .

Mutational analysis of yeast PCNA has suggested separate roles for PCNA in DNA replication and repairs $[18,19]$. For example; PCNA mutants like pol30-9 (ED104,105AA) and pol30-22 (DE256,257AA) show sensitivity to DNA methylating agents and UV light, however they grow normally on medium containing a replication inhibitor hydroxyurea, and do not elicit any temperature sensitivity. Similarly pcna-201 (C22Y) and pcna-204 (C81R) alleles generate frame-shift and substitution mutations due to reduced MMR efficiency but do not show any defects in replication or other repair processes. In vitro binding studies revealed a compromised interaction of these mutant proteins with MSH2 and MSH6 proteins. A number of PCNA mutants have also been characterized those are defective in both DNA replication and repair processes. Alleles like pcna-79 that has IL126, 128AA mutations in the IDCL, and pcna-90 that carries PK252, 253AA mutations in the carboxyl terminal tail exhibit growth defects, elevated sensitivity to DNA-damaging agents, and higher rates of spontaneous mutations [17]. Biochemical characterization of some of these mutant PCNAs e.g. PCNA-240 often showed structural alteration and reduced stability of the trimeric ring [19].

PCNA has been characterized in human, rat, budding and fission yeasts, protozoan, flies, Arabidopsis, and many archaeal species [7, 20-25]. However, no such studies of PCNA from pathogenic Candida albicans or any other Candida species have been carried out till date. C. albicans, an opportunistic pathogen, which asymptomatically colonizes humans, can cause severe infection in immounocompromised people or when the microbiotic balance is disturbed [26, 27]. Systemic fungal infections by $C$. albicans are life threatening and of great concern to human health [28]. Study of the fundamental cellular processes such as DNA replication, repair and recombination in this pathogenic yeast and their parallel comparison with nonpathogenic S. cerevisiae is crucial to unravel the distinct biochemical processes or factors, which may be targeted to control infections/diseases. DNA repair mechanisms like base excision repair (BER) and nucleotide excision repair (NER) are well studied in $C$. albicans; and interestingly unlike in S. cerevisiae, DNA repair genes such as NTG1, APN1, OGG1, RAD2 and RAD10 do not to play any crucial roles in mutagenesis, genomic stability and drug resistance phenotype in $C$. albicans [29]. Similarly, proteins involved in mismatch repair (MMR) and non-homologous end joining (NHEJ) also do not contribute significantly to the Candida genomic stability; however defects in double-strand break repair enhance genomic instability [30]. Role of DNA replication components in genomic stability have not yet been explored in this pathogenic fungus. Thus, to initiate understanding of DNA replication in this model organism, in this study we report on the biochemical characterization of CaPCNA as well as its role in DNA replication and repair in S. cerevisiae.

\section{Results}

Identification, sequence analysis and structural comparison of CaPCNA with S. cerevisiae PCNA

To identify a putative homologue of $S$. cerevisiae PCNA, the amino acid sequence was used for BLAST analysis. BLAST analysis identified a C. albicans SC5314 homologue that corresponds to orf19.4616 (alias $\mathrm{CaO} 19.12086$ ) in CGD with a score of $6 \mathrm{e}^{-103}$, identity of $54 \%$ and similarity of $81 \%$. Henceforth we refer to this orf as CaPCNA. Interestingly, CLUSTAL W alignment analysis showed $42 \%$ and $35 \%$ identity of Candida and yeast PCNA with that of human, respectively (Fig 1). In addition, the sequence identity among the PCNAs was found throughout

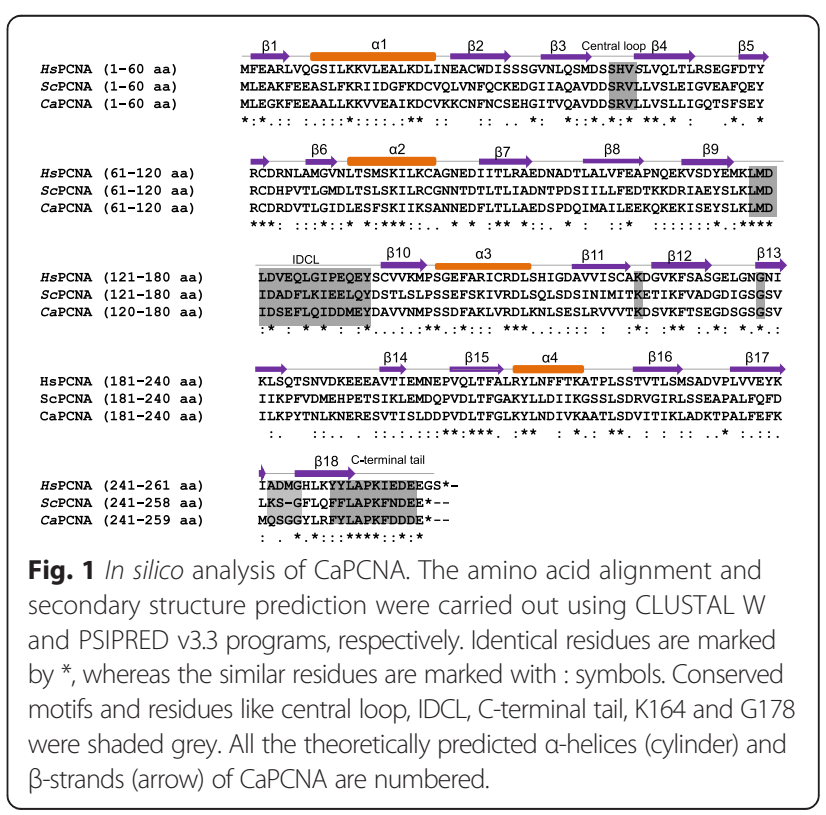


the orfs in clusters of three to four amino acids. CaPCNA sequence encodes a predicted $29 \mathrm{kDa}$ protein composed of 259 amino acids which is two amino acids shorter than HsPCNA (28.7 $\mathrm{kDa})$ but one amino acid longer than ScPCNA (28.9 kDa) at its carboxyl terminus. Alignment also showed very high degree of amino acid conservation in the central loop (43SRV45), inter domain connecting loop (IDCL, 118L-_D134) as well in the C-terminal tail (149 F-E259); and these domains are known to interact with different protein factors during DNA synthesis. Regulatory residues like Lys164 that undergoes ubiquitylation and sumoylation; and Gly178 which is involved in stability of the PCNA ring are found to be conserved [31, 32].

Since the sliding clamps from all domains of life possess superimposable three-dimensional structures and primary sequence of CaPCNA showed remarkable similarity, we examined the structure of putative CaPCNA by using in silico approach. By using SWISS MODEL and taking ScPCNA pdb structures as template, model structure of $\mathrm{CaPCNA}$ was predicted
(Fig. 2). CaPCNA also forms a toroidal shaped homotrimeric ring, and the superimposition of the modeled complex with the template ScPCNA showed a root mean square deviation (RMSD) of $0.48 \AA$ (Fig. $2 \mathrm{~B}$ and $\mathrm{C}$ ). The Ramachandran plot showed $88.2 \%$ residues in the most favoured and $11.8 \%$ residues in the additional allowed region (Fig. 2 D) confirming the acceptability of the model structure. In the monomeric structure, CaPCNA is composed of two identical globular domains, one with $\beta 1-\alpha 1-\beta 2-\beta 3-\beta 4-\beta 5-\beta 6-\alpha 2-$ $\beta 7-\beta 8-\beta 9$ and the other with $\beta 10-\alpha 3-\beta 11-\beta 12-\beta 13-\beta 14-$ $\beta 15-\alpha 4-\beta 16-\beta 17-\beta 18$, joined by an IDCL (in blue, Fig. 2 A). The minor difference in CaPCNA model structure was noticed in the loop that connects $\beta 17$ and $\beta 18$ at the C-terminal tail (Fig. 2 C).

\section{CaPCNA forms a stable homotrimeric ring}

To characterize CaPCNA further, the orf was PCR amplified and expressed in bacterial cells. The orf was in frame with N-terminal GST and a Prescision protease site was strategically placed to cleave PCNA from GST.

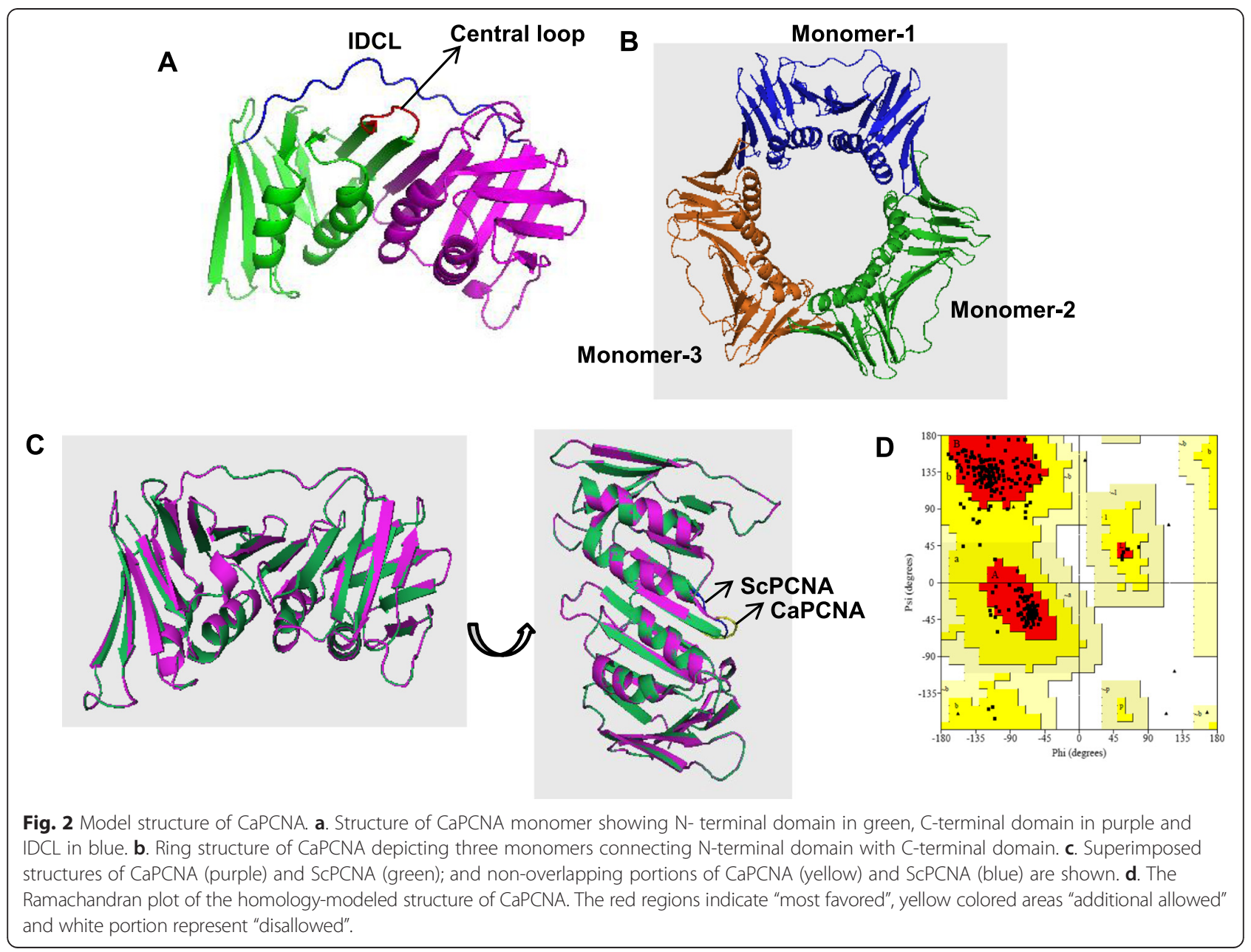


Using glutathione sepharose beads as described in methods, wild type and mutant PCNA were purified to near homogeneity. As predicted, CaPCNA (29 kDa, pI 4.54) and its G178S mutant migrated relatively slower than ScPCNA (28 kDa, pI 4.42) when analyzed by SDS-PAGE (Fig. 3 A, compare lane 2 with $3 \& 4$ ). Structural modeling of CaPCNA sequence predicted it to form an oligomer of three subunits, to authenticate the prediction the purified proteins were analyzed by native PAGE. Expectedly, CaPCNA migrated at a position similar to ScPCNA. As the latter is a homotrimer, this observation suggested that CaPCNA also forms a stable trimer (Fig. 3 B, lane 1 \& 3). A slightly faster mobility of ScPCNA may be attributed to its lower pI comparison to CaPCNA. Biochemical and structural characterization of ScPCNA G178S mutant suggested that G178 residue resides in the interface of the two monomers and due to mutation to serine, it destabilizes the PCNA ring; therefore it remains mostly as monomer [33]. To ascertain co-migration of wild type CaPCNA with ScPCNA in native PAGE is because of oligomerisation of monomers and not due to any abnormality in CaPCNA, a G178S mutant protein was further analyzed. As reported earlier, CaPCNA G178S mutant (Fig. 3 B, lane 2) migrated faster than the wild type Candida and yeast PCNA, probably as monomer and suggesting an evolutionary conservation of its role in stabilization of PCNA ring. Size exclusion chromatography (Fig. $3 \mathrm{C}$ ) confirmed the trimeric nature of the protein as wild type CaPCNA and ScPCNA eluted around $\sim 90 \mathrm{kDa}(\sim 1.6 \mathrm{ml}$ elution volume, blue line). However candida G178S mutant PCNA eluted much later as $\sim 30 \mathrm{kDa}(\sim 2.3 \mathrm{ml}$ elution volume, red line) when referred to the molecular weight standards (Fig. 3 C). Further we verified the stability of the PCNA trimers by

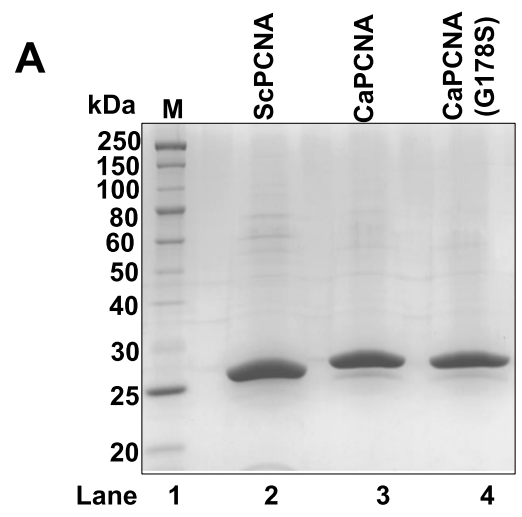

B
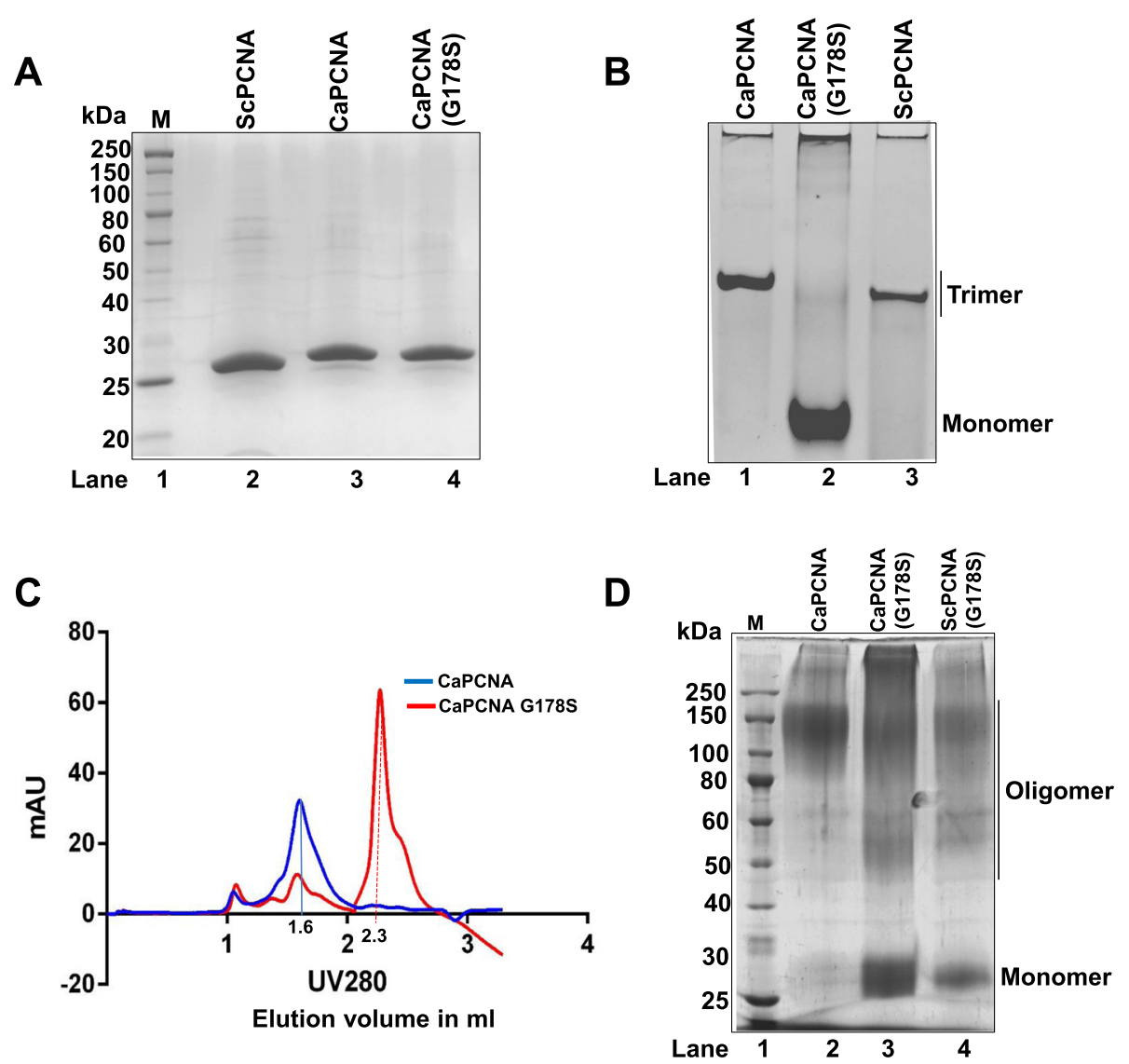

Fig. 3 Purification and biochemical analysis of PCNAs. The wild type and mutant PCNAs were purified and $\sim 1 \mu \mathrm{g}$ of each protein was analyzed. a. Purified proteins were resolved in SDS-12 \% polyacrylamide gel. Lanes 1, Molecular weight standards; 2, ScPCNA; 3, CaPCNA; and 4, CaPCNA G178S. c. Purified proteins were resolved in $12 \%$ non-denaturing polyacrylamide gel. Lanes 1, CaPCNA; 2, CaPCNA G178S; and 3. ScPCNA. c. Size exclusion chromatograms of wild type (blue) and G178S mutant (red) CaPCNAs with the peak fractionation at $\sim 1.6 \mathrm{ml}$ and $\sim 2.3 \mathrm{ml}$ elution volume, respectively, were shown. d. Glutaraldehyde crosslinked $20 \mu \mathrm{g}$ of CaPCNA (lane 2) or CaPCNA G178S (lane 3) or ScPCNA G178S (lane 4) proteins were resolved in SDS-12\% polyacrylamide gel. Monomer ( $29 \mathrm{kDa})$ and oligomeric PCNAs ( 60-180 kDa) are marked. Lane 1, Molecular weight standards. 


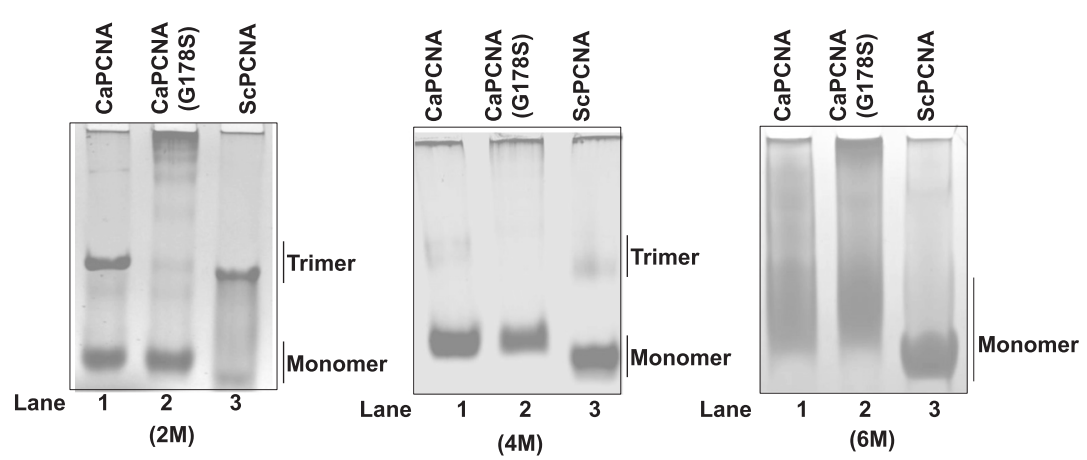

Fig. 4 Stability of PCNAs. Purified proteins were resolved in $12 \%$ polyacrylamide gel containing $2 \mathrm{M}, 4 \mathrm{M}$, and $6 \mathrm{M}$ urea as indicated, and stained by Coomassie Brilliant Blue R250. Lanes 1, CaPCNA; 2, CaPCNA G1785; and 3. ScPCNA.

resolving them on a urea containing PAGE (Fig. 4). Both Candida and budding yeast PCNA showed maximum stability in $2 \mathrm{M}$ urea and complete urea dependent denaturation to monomer at $6 \mathrm{M}$ urea. Here the CaPCNA G178S mutant protein served as a marker of monomeric form of PCNA (Fig. 4 lane 2).

Although all eukaryotic PCNAs characterized so far form a stable trimer in vitro, the exact composition of PCNA ring in the cell is still not clear as formaldehyde cross-linked $\mathrm{CHO}$ cells extract or purified human PCNA resulted in formation of a double trimeric PCNA [34]. Mutational analysis suggested the role of R5 and K110 amino acids of human PCNA in doublet-trimer formation. Reagents like formaldehyde or glutaraldehyde cross-links neighboring lysine or arginine residues of monomers by amine bonds to form oligomers. As these residues ( $\mathrm{K} 5$ and $\mathrm{K} 110$ ) are also conserved in CaPCNA, purified recombinant proteins were cross-linked and analyzed on $12 \%$ SDS-PAGE (Fig. 3D). Like HsPCNA, CaPCNA showed a smear ranging from $\sim 90-180 \mathrm{kDa}$ (trimer and double trimer) whereas G178S PCNA mutant migrated in multiple forms by glutaraldehyde cross-linking and predominantly as monomers (29 kDa).
Mutant PCNA also formed dimeric PCNA ( 60 kDa). Similar results are also obtained with ScPCNA and its G178S mutant (Fig. 3D lane 4). In consistent with earlier findings, our study also suggests that PCNA from C. albicans and S. cerevisiae may also exist as a doubletrimer in the cell.

\section{CaPCNA physically interacts with yeast DNA polymerase eta (ScPoln)}

PCNA functions as a docking site for DNA polymerases and other proteins during various processes of DNA transaction. In order to function, CaPCNA needs to interact with DNA polymerases and other associated proteins. Yeast DNA polymerase eta (ScPoln) that takes part in translesion DNA synthesis [35] was used as a candidate polymerase for physical interaction study by surface plasmon resonance. We immobilized CaPCNA or ScPCNA on a GLC- chip to determine the binding affinity for ScPoln. As a control, required amount of BSA was also immobilized. When ScPoln was passed over BSA, we did not see any significant increase in response unit where as it showed $\sim 250$ and $\sim 650$ RU for ScPCNA and $\mathrm{CaPCNA}$, as ligands respectively (Fig. 5) suggesting

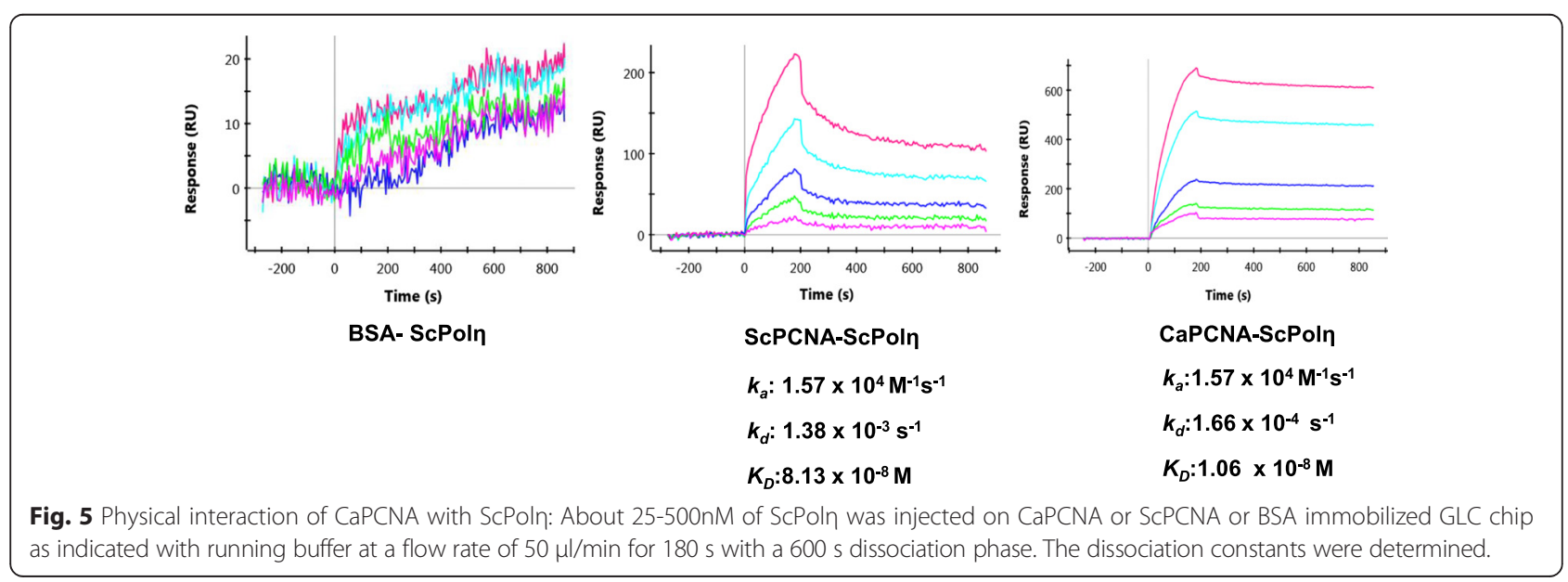


the tight binding between PCNAs and DNA polymerase. The rate of dissociation of ScPoln from ScPCNA surface ( $\left.k d: 1.38 \times 10^{-3} \mathrm{~s}-1\right)$ was comparable to that from CaPCNA immobilized surface $\left(k d: 1.66 \times 10^{-4} \mathrm{~s}-1\right)$. The $K_{D}$ values of CaPCNA and ScPCNA for ScPoln were determined as $10.6 \mathrm{nM}$ and $80.13 \mathrm{nM}$, respectively.

\section{CaPCNA complements essential function of POL30 in S. cerevisiae}

POL3O gene in any organism is indispensable for cell survival. Because our biochemical and structural modelling studies suggested CaPCNA to be alike of ScPCNA, it compelled us to examine whether CaPCNA can perform the essential functions of yeast POL3O and support cell viability of the genomic null strain. To achieve our goal CaPCNA was expressed either under its own promoter or under a yeast constitutive promoter
$A D H 1$ in genomic deletion strains of $S$. cerevisiae but survives due to presence of a plasmid bearing ScPCNA. The segregation of plasmids was carried out to replace the ScPCNA with CaPCNA by two different approaches. In one approach, YTS9 strain which is null for genomic POL30 but carrying YCP-ScPOL30 DE41, 42AA-TRP1 plasmid for survival was used to obtain transformants harbouring various CaPCNA plasmids (URA3) on SD media lacking tryptophan and uracil. Attempt to cure the retained plasmid was carried out by repeated sub-culturing of the transformants on SD-uracil liquid media as described in methods. About 30 isolated colonies from each set were streaked on SD-uracil and SD-tryptophan plates. The percentage of curing of resident plasmid was scored and a representative figure has been shown (Fig. 6 A). The lack of growth on SD-tryptophan plate but growth on SD-uracil will suggest complete curing of the resident

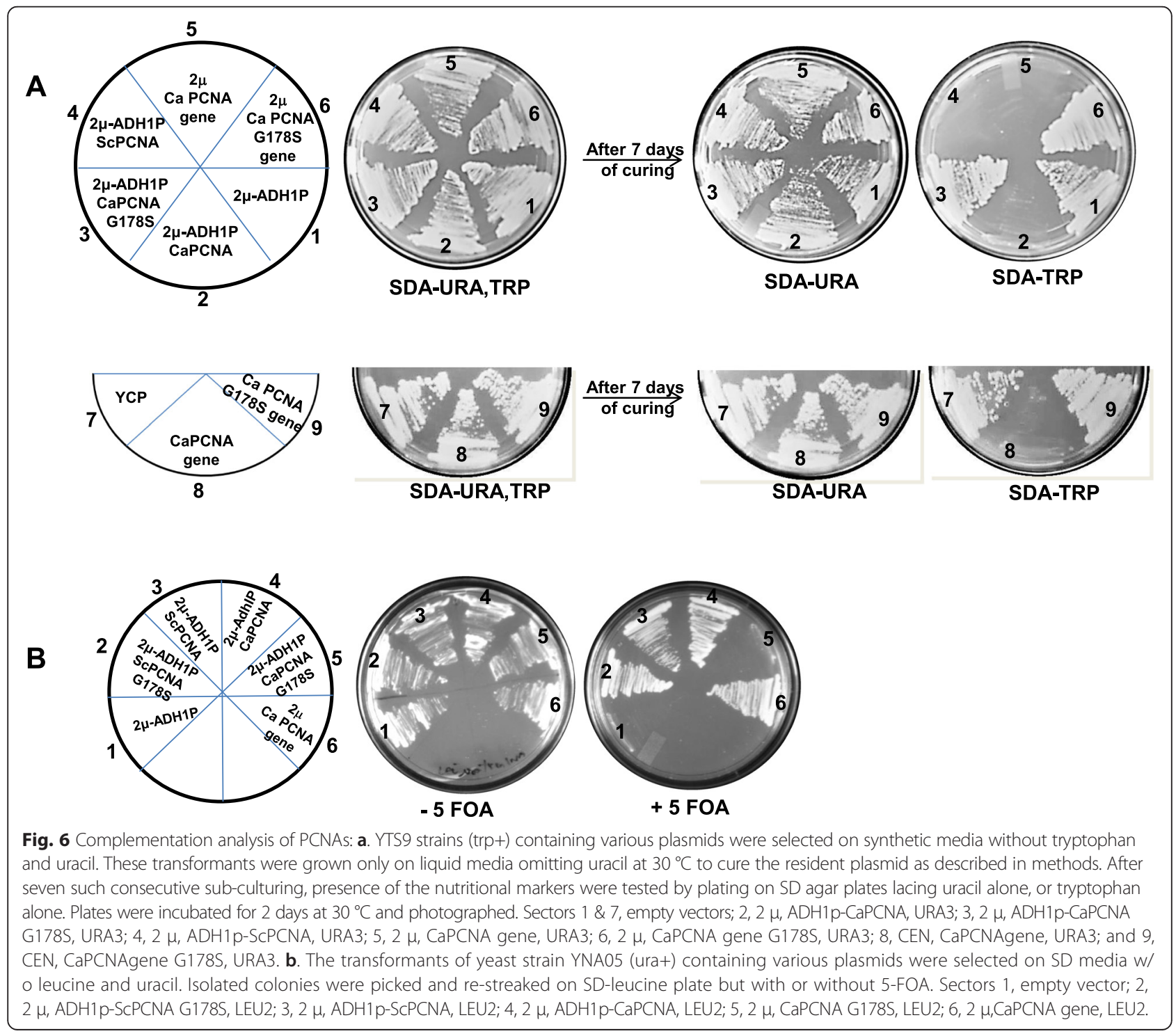


PCNA and complementation due to incoming plasmid. Strains containing CaPCNA or its gene in both CEN/2 $\mu$ vectors were able to replace the resident plasmid (Fig. 6 A sectors 2, 5 and 8), and about $100 \%$ efficient curing was achievable. Similar result was also obtained for incoming ScPCNA but not for the vector controls as both the nutritional marker phenotypes (URA and TRP) were retained (Fig. 6 A compare sector 4 with 1 and 7).

In the other approach various CaPCNA constructs were transformed into a yeast strain YNA05 in which the chromosomal POL3O gene was deleted and the cell viability was maintained by ADH1p-ScPCNA-URA3 based plasmid to allow positive as well as counter selection of this plasmid by 5 -FOA. As shown in Fig. 6B, cells harboring CaPCNA or ScPCNA but not the vector control could grow on 5FOA containing SD medium, in which the resident plasmid (URA3) was negatively selected (compare lane 1 with 3,4 and 6). Taken together, we conclude that CaPCNA is able to functionally complement the essential functions of yeast $P O L 30$ and supports cell viability.

\section{CaPCNA G178S mutant functions differently in yeast}

The pol30-178, also known as rev6-1 S. cerevisiae allele that carries a genomic mutation of G178 to serine in PCNA is well characterized [32]. Biochemical characterizations from our study as well as from those of other's suggested the crucial role of this residue in stabilizing the PCNA ring as both Candida and yeast G178S mutant proteins remained mostly as monomers in vitro. Although pol30-178 allele strain grows normally, surprisingly, Candida G178S did not complement the essential function of ScPOL30 when plasmid segregation was carried out in both YTS9 and YNA05 strains (Fig. 6A sectors 3, 6 and 9). However, the incoming ScPCNA G178S was able to complement (Fig. 6B, compare sector 2 with 5) the cell growth on FOA plate. Our observations suggest that presumably ScPCNA G178S is able to form a DNA clamp in vivo, whereas Candida mutant is unable to form a functional clamp in yeast.

\section{CaPCNA exhibits slow growth phenotype in yeast and partially complements replication defects caused by hydroxyurea}

To analyze the role of CaPCNA in DNA replication, growth rates of $P O L 30$ knock out yeast strains expressing CaPCNA in single to multi-copy plasmids were monitored. Interestingly, strains harbouring CaPCNA formed smaller sized colonies and grew relatively slower than that with wild type ScPCNA, and accordingly, strain having CaPCNA in a CEN plasmid (low copy number) grew even slower (Fig. 7A, see Additional file 1: Table S1). As previously reported, we also observed a slow growth phenotype for YTS9 strain; and the slow growth phenotype was attributed to the weak binding of mutant PCNA (DE41, 42AA) with DNA and DNA polymerases [18]. Similarly, yeast strain expressing CaPCNA or ScPCNA DE41, 42AA showed temperature sensitivity at $14{ }^{\circ} \mathrm{C}$ and $35{ }^{\circ} \mathrm{C}$ (data not shown). To ascertain the slow growth defects of various yeast strains is not due to the difference in the expression levels of PCNAs rather due to the intrinsic properties of CaPCNA, RT-PCR was carried out to check the mRNA level of both the PCNA. Our result showed that there is no noticeable difference in the expression between the two PCNAs under $A D H 1$ or under its own promoter (Fig. 7B, compare lanes 2, 4 with 3, 5). The native expression level of yeast DNA polymerase eta was
A

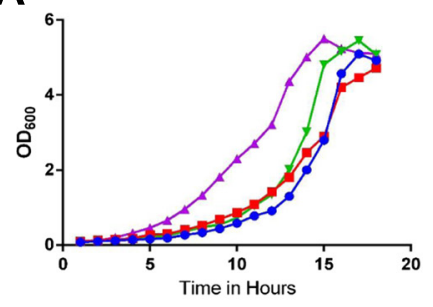

$\rightarrow$ YCP-SCPCNA gene DE41,42AA

$\rightarrow$-YCP-ADH1p-CaPCNA

- YEP-ADH1p-CaPCNA

$\mp$ YEP-ADH1P-ScPCNA

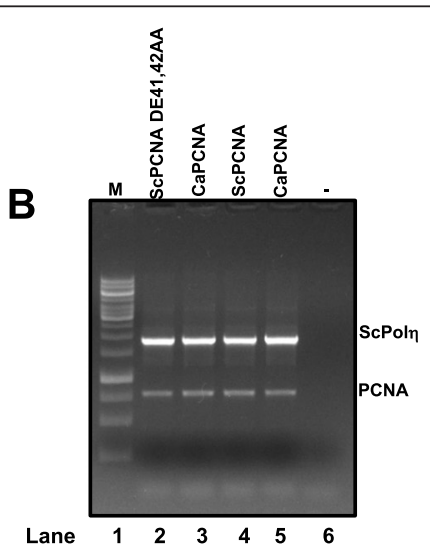

Fig. 7 Growth curves of various yeast strains expressing CaPCNA: a. Genomic POL30 deletion yeast strains containing YEP-ADH1P-SCPCNA (-- $\mathbf{\Delta}-$ ), YCP-ADH1 p-CaPCNA (---) , YEP-ADH1 p-CaPCNA (-- - -), and YCP-SCPCNA gene with DE41,42AA (- $\bullet-)$ were grown in 100 ml YPD liquid medium at $30{ }^{\circ} \mathrm{C}$ and absorbance at $600 \mathrm{~nm}$ were measured at regular intervals. The plot was an average three sets of experiment. $\mathbf{b}$. Total RNA from the above strains were isolated and semi-quantitive Reverse Trascriptase PCR was carried out. The PCR products were analyzed in a $1 \%$ agarose gel electrophoresis. Lane 1, 1 KB DNA ladder; Lane 2 c-DNAs of ScPCNA DE41,42AA and ScPoln; Lane 3 c-DNAs of CaPCNA and ScPoln; Lane 4 c-DNAs of ScPCNA and ScPoln; Lane 5 c-DNAs of CaPCNA and ScPoln; Lane 6 no c-DNA control reaction. 


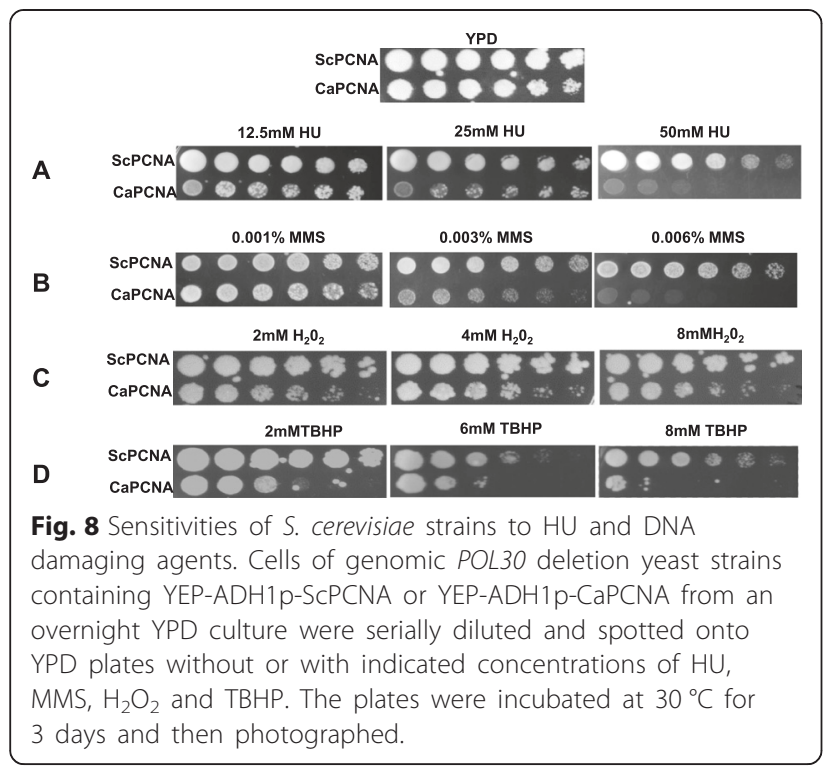

checked and used as a loading control. The relative fold change of band intensities of PCNA vs ScPoln varies from 0.7 to 0.9 (see Additional file 2: Table S2).

Hydroxyurea depletes cellular dNTPs level and has been widely used as a replication inhibitor. When we examined susceptibility of these strains to $\mathrm{HU}$ (Fig. 8A), yeast strain ectopically expressing ScPCNA (YEP-ADH1p-ScPCNA) did not show any significant sensitivity up to $50 \mathrm{mM} \mathrm{HU}$, rather surprisingly strain expressing CaPCNA (YEP-ADH1p-CaPCNA) showed hypersensitivity to similar concentration of $\mathrm{HU}$, as growth was quite adversely affected on YPD plates containing $50 \mathrm{mM}$ HU. However growth at $12.5 \mathrm{mM}$ $\mathrm{HU}$ for both the strains remained unaffected. In this assay also both the strains displayed differential growth rates and yeast strain expressing homologous PCNA was considerably over-growing the other. Although CaPCNA complemented essential nature of ScPOL3O and was able to support DNA replication, it was evident from the growth curve, temperature and $\mathrm{HU}$ sensitivity analyses that CaPCNA is not as efficient as ScPCNA as far as DNA replication is concerned in S. cerevisiae.

\section{Ectopic expression of CaPCNA caused sensitivity to DNA damaging agents in yeast}

Eukaryotic PCNA functions in DNA repair in addition to its role in DNA replication. In order to study the function of CaPCNA in DNA repair, strains were subjected to various damaging agents like MMS, $\mathrm{H}_{2} \mathrm{O}_{2}$ and TBHP (Fig. 8B-D). Like treatment with $\mathrm{HU}$, strains expressing CaPCNA displayed significant sensitivity to these agents than that containing ScPCNA in yeast. MMS an alkylating agent methylates DNA mainly to generate adducts like
N7-methylguanine and N3-methyl adenine; and is highly mutagenic. About $0.006 \%$ MMS is highly toxic to yeast bearing CaPCNA but strain having ScPCNA showed negligible sensitivity (Fig. 8 B). $\mathrm{H}_{2} \mathrm{O}_{2}$ and TBHP increases oxidative stress in a cell and generate oxidized DNA lesions. At $8 \mathrm{mM}$ of these reagents, growth of yeast bearing CaPCNA but not of strain having ScPCNA was impaired (Fig. 8C and D). Taken together, we conclude that CaPCNA is relatively less efficient in coordinating DNA repair processes in yeast.

\section{C. albicans is genetically resistant to DNA damaging} agents in comparison to nonpathogenic S. cerevisiae Heterologous expression of CaPCNA in non-pathogenic $S$. cerevisiae resulted in sensitivity to DNA damaging agents, however during infection $C$. albicans evades various attacks of ROS/RNI species generated by innate immune cells [36]. Whether in a homologous system CaPCNA provides any protective role, a comparative study of susceptibility by wild type strains of C. albicans and yeast to DNA damaging agents was carried out (Fig. 9). When equal number cells were diluted and spotted; interestingly, C. albicans strain SC5314 which is a commonly used laboratory wild type strain overgrew $S$. cerevisiae strain EMY74.7, a derivative of widely used DBY747. So the retardation of growth rate in Fig. 7A where we checked growth rates of yeast containing CaPCNA is not due to the characteristic CaPCNA rather because of lack of species specific interaction with replication components. Despite the differences in the growth rate, Candida SC5314 exhibited moderate sensitivity to $\mathrm{HU}$ than yeast EMY74.7 at $50 \mathrm{mM} \mathrm{HU}$, the reason for such a phenotype requires further extensive analysis (Fig. 9 A). The C. albicans SC5314 showed tolerance to DNA damaging agents like MMS, $\mathrm{H}_{2} \mathrm{O}_{2}$,

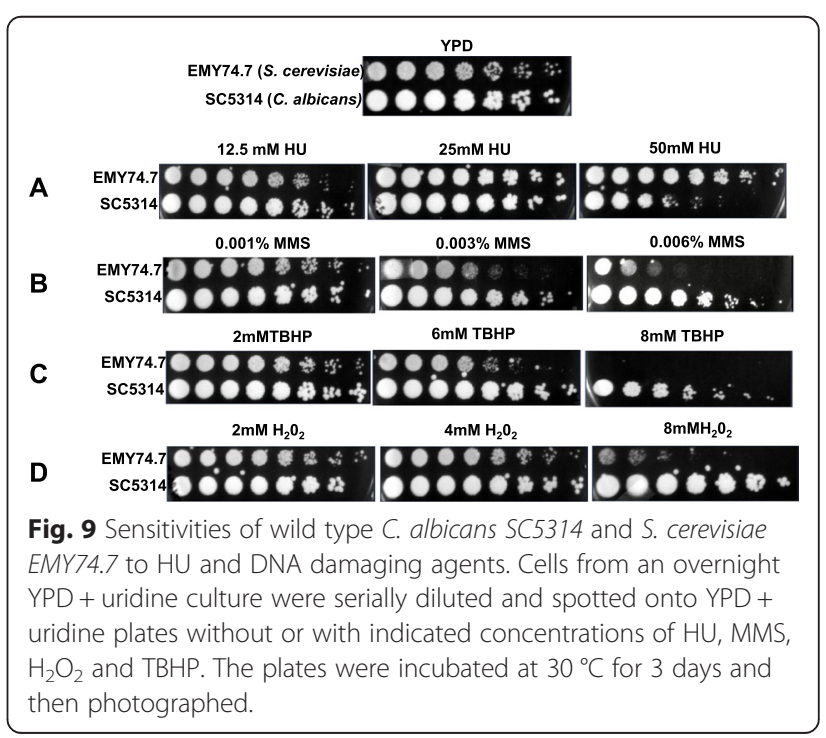


and TBHP unlike yeast strain expressing CaPCNA; and at same or lower concentration of reagents, a significant impairment of growth of EMY74.7 was observed. In a different study, similar results have been reported earlier by using diploid strains of $S$. cerevisiae BY4743 and C. albicans DKCa39 [29, 30]. While one copy of PCNA gene can be easily deleted from diploid S. cerevisiae, because of haplo-insufficiency similar deletion was not achievable in C. albicans $[37,38]$. Taken all together we suggest that the fungal pathogen C. albicans is genetically evolved to be resistant to DNA damages in comparison to nonpathogenic budding yeast; and CaPCNA dependent DNA damage tolerance pathways could play a crucial role in addition to other cellular mechanisms like efficient drug efflux pumps, thicker cell wall and any other components present in C. albicans to maintain genomic stability.

\section{Discussion}

Systemic infections caused by Candida albicans are life threatening in immune-compromised individuals [28]. In order to kill the microbes, the innate immune cells like macrophages phagocytize Candida cells, generate ROS/ RNI that damage DNA [26, 36]. Therefore C. albicans becomes an interesting model system to understand mechanisms of DNA transaction processes and their parallel comparison with well-studied nonpathogenic $S$. cerevisiae is crucial to unravel the distinct biochemical processes or factors, which may be targeted to control infections/diseases. For maintenance of genomic stability and cell survival, PCNA plays an essential role and regulate recruiting of factors such as DNA polymerases during replication, DNA repair enzymes, and proteins involved in recombination and cell cycle [1]. The Candida Genome Database annotates C. albicans orf19.4616 as yeast PCNA homologue [37] and mRNA expression profiling study during cell cycle suggested overexpression of this ORF during G1/S transition along with other proteins involved in DNA synthesis [39]. Separation of proteins from Candida cells by 2-D gel electrophoresis revealed an increased amount of CaPol30 when cells were growing exponentially than the stationary phase cells [40]. Similarly, genome wide expression profiling in response to fungal drugs like 5-FC suggested increased expression of POL30 [41]. Tyrosol, a quorum-sensing molecule in C. albicans has also been found to regulate the expression PCNA [42]. Despite these facts, PCNA from $C$. albicans had not been characterized until this study. In this report for the first time we have presented an extensive study on cloning and characterization of CaPCNA; and reported functional similarities and differences between CaPCNA and ScPCNA.
Our study suggests that orf19.4616 encodes for a classical eukaryotic DNA clamp. Primary sequence and molecular modeling analyses suggest a great degree of conservation in various motifs and the three dimensional structures among PCNAs. Like other eukaryotic PCNAs, CaPCNA also forms a ring of three monomers; each consisting of two topologically similar globular domains connected by a hydrophobic loop. The folding of inter domain connecting loop of CaPCNA is also undistinguishable from that of ScPCNA, as IDCL is known to bind to DNA polymerases, accordingly a conserved interaction with yeast DNA polymerase eta was also established. For the first time, we designed a urea-PAGE based study to check the stability of PCNA ring and found that both candida and yeast PCNA were equally resistant to urea dependent denaturation. Glutaraldehyde cross linking experiment also revealed formation of double trimers as has been shown in the case of human PCNA [34]. Although the exact role of double trimeric PCNA ring has not been established, its physiological advantage of interacting with multiple partners at a given time and process can be speculated.

Remarkable structural conservation and homology in primary sequences of CaPCNA resulted in complementation of essential function of yeast PCNA deletion mutant. Similar observation has been reported for human PCNA supporting viability of a Schizosaccharomyces pombe deletion mutant [21]. The PCNA of Drosophila melanogaster but of S. cerevisiae facilitates in vitro DNA replication of SV40 [43]. This suggests existence of similar interactions between PCNA and replicative DNA polymerases; and probably the binding sites are also conserved in eukaryotes. Simultaneously, it also implies that ScRFC, the clamp loader cannot differentiate CaPCNA against ScPCNA while loading. This finding is well supported by an observation that the PCNApartner interaction networks are coevolved in $S$. cerevisiae and C. albicans due to their highly conserved interaction regions in both PCNA and interacting proteins. Therefore PCNAs of these two fugal species are in the same compatibility group distinguished from that of $Y$. lipolytica, A. nidulans, $N$. crassa, and S. pombe [44]. The comparatively slow growth phenotype, susceptibility to non-permissive temperatures and sensitivity to $\mathrm{HU}$ of CaPCNA containing yeast strain could be due to absence of some of the critical contacts between CaPCNA and yeast replicative polymerases like Pol $\delta$ or Pole [3]; and thereby although supporting DNA replication, but with reduced efficiency. In fact, DmPCNA also supports in vitro SV40 DNA replication with compromised efficiency [43]. However, optimal growth was observed in the wild type Candida strains SC5314 and DKCa39; and even better 
growth rate in comparison to wild type yeast strains suggesting a species-specific interaction between PCNA and its partner is beneficial during DNA replication. Biochemical studies suggested G178S mutants of Candida and yeast PCNA behave similarly. However, CaPCNA G178S mutant did not complement yeast for its deficiency of ScPCNA whereas the corresponding yeast PCNA mutant did. Also the pol30-178 of S. cerevisiae allelic strain that carries a genomic mutation of G178 to serine mutation in PCNA survives and did not show any replication defects [32]. Another pcna-52 allele which carries S115P mutation and the corresponding purified proteins remaining as monomers during gel filtration and even multimers by crosslinking experiments with glutaraldehyde have also been reported [18]. Although these mutant proteins abundantly form monomers and some population of multimers in vitro, apparently in the cell the PCNA trimeric rings get stabilized by some yet to be identified mechanism(s).

An array of site directed and random mutants of ScPCNA have been extensively studied to understand its differential role in DNA replication and repair processes $[18,19]$. Most of the mutations were on the outer surface of the ring required for protein-protein interactions and exhibited wide range of sensitivity to MMS, UV and HU. One class of mutants like pcna-6 (DE41,42AA), pol30-45 (RDDE61,63,256,257AAAA), pol30-46 (EDDE104,105,256, 257AAAA), pcna-79 (IL126,128AA) and pcna-90 (PK252, 253AA) were susceptible to hydroxyurea, exhibited compromised growth and DNA repair defects. A number of other PCNA mutants have also been characterized those are defective in replication also show defects in DNA repair. Whereas second class of mutants like pol30-9 (ED104,105AA), pol30-22 (DE256,257AA), pcna-201 (C22Y) and pcna-204 (C81R) alleles did not show any phenotypes linked to DNA replication defects but showed DNA repair defects. Particularly, pcna-201 (C22Y) and pcna-204 (C81R) alleles are defective in mismatch repair. Limitation of these analyses is that most of the PCNA that showed defects in replication and repair carry multiple mutations that may alter the structure and property of PCNA. As biochemical characterization of some of these mutant PCNAs like PCNA-240, PCNA-45 showed formation of monomeric PCNA and compromised interaction with DNA repair related proteins [19]; thus it may be argued against the suggestion of separate role of PCNA in replication and repair. Therefore similar studies with a naturally occurring eukaryotic PCNA will be a novel approach to delineate the precise roles of PCNA in DNA replication or in repair. In this study not only we have first time reported characterization of CaPCNA, but also we have presented a naturally occurring PCNA form C. albicans whose mere presence in yeast showed characteristics of replication defects like slow growth, smaller colony size, temperature susceptibility and sensitivity to HU; and DNA repair defects like sensitivity to DNA damages with agents like MMS, $\mathrm{H}_{2} \mathrm{O}_{2}$ and TBHP. It was unexpected as interestingly, PCNA2 from $A$. thaliana plant not only supported viability of pol30 $S$ S. cerevisiae strain, it also conferred resistance to DNA damaging agents [45]. Nevertheless, CaPCNA belongs to a class of ScPCNA mutants like pcna-6, $-79,-90$ and others that show both DNA replication and repair defects but support cell viability.

\section{Conclusions}

We conclude that orf19.4616 encodes for a classical eukaryotic DNA clamp and shares high degree of similarities in its biochemical and structural features with ScPCNA. Although both S. cerevisiae and C. albicans belong to same fungal family of Saccharomycetaceae and despite both the PCNAs possessing common features, CaPCNA is not fully compatible in replacing ScPCNA in processes like DNA replication and repair in yeast. Remarkable tolerance to DNA damaging agents phenotype exhibited by $C$. albicans strains compared to yeast strains suggest that $C$. albicans being an opportunistic pathogen genetically evolved to tolerate extreme conditions and probably to escape from attack by macrophages to maintain its genomic blue prints. Unlike S. cerevisiae, as BER, NER, MMR and NHEJ pathways have been ruled out to play a major role in genomic stability in C. albicans [29, 30], PCNA coordinating other DNA damage tolerance pathways such as replication, translesion DNA synthesis and recombination could be playing an important role that requires further investigation. Considering all the evidences, we conclude that despite structural and physiochemical similarities; there are distinct functional differences between ScPCNA and CaPCNA, and the ways both the strains maintain their genome stability. Hence PCNA may play a critical role in the development of systemic candidiasis and targeting PCNA could develop a new means to combat C. albicans infection.

\section{Materials and Methods:}

\section{Oligonucleotides, strains and media}

The oligonucleotides used in this study were procured from Integrated DNA Technologies (IDT, USA). S. cerevisiae EMY74.7 and Candida albicans SC5314 were used as wild type strains [37]. A protease deficient yeast strain YRP654 was used for protein expression of ScPoln [46]. For plasmid segregation analysis, YTS9 which is a POL30 genomic null yeast strain supported by a YCplac22 (CEN, TRP) plasmid derived POL30 with DD41,42AA mutations was used. Various yeast strains obtained by transforming different PCNA constructs to YTS9 and others used in this study 
are described in Table 1. C. albicans and S. cerevisiae strains were grown on YPD media with or without DNA damaging agents or on various synthetic drop out media as required.

\section{Generation of PCNA constructs}

A $50 \mu \mathrm{l}$ PCR reaction was carried out containing $100 \mathrm{ng}$ of SC5314 genomic DNA, $250 \mu \mathrm{M}$ dNTPs, $1 \times \mathrm{Pfx}$ enzyme buffer, $1.5 \mathrm{mM} \mathrm{Mg} \mathrm{SO}_{4}$ and $2 \mathrm{U}$ of Pfx DNA polymerase (Invitrogen) and 20pmol each of the primers NAP31 (5'-GGC CAA GCT TGG ATC CAC ATA TGT TAG AAG GTA AAT TTG AAG -3') and NAP32 (5'- GGC CGA ATT CGG ATC CCT ACT CAT CAT CAT CG-3') for the orf 19.4616; and NAP29 (5'- CCG GAA GCT TAC GAT GCT TAT AGA TTG-3') and NAP30 (5'-GGC CGA ATT CGA AGA GTA GTT AAC ATT TG-3') for the gene, respectively. PCR conditions included initial heating at $95^{\circ} \mathrm{C}$ for 3 ' followed by 34 cycles at $95{ }^{\circ} \mathrm{C}$ for $30 \mathrm{~s}, 48{ }^{\circ} \mathrm{C}$ for $45 \mathrm{~s}, 68{ }^{\circ} \mathrm{C}$ for $50 \mathrm{~s}$ (orf) or $1^{\prime}$ 30s (gene). Amplified PCR products (780 and $1449 \mathrm{bp}$ ) were purified, digested with HindIII-EcoRI, and cloned into the same sites of pUC19. Further the clones were authenticated by sequencing. The pathogenic yeast C. albicans decodes CUG codon as serine instead of leucine, however CaPCNA does not harbour any such codons in its orf; and therefore no further modification was required for expression [37, 47]. The BamHI fragment containing wild type or G178S PCNA orf was further subcloned into BglII site of a bacterial expressed amino terminal GST-tag construct. Similar fragments were also subcloned into BamHI site of an $A D H 1$ promoter based yeast expression system. The PCNA gene was also subcloned to yeast vectors (YEp/YCp) for complementation analysis.

\section{Site directed mutagenesis}

G178S mutation was generated on respective pUC19 constructs by an inverse PCR approach using Pfx DNA polymerase with primer pairs NAP218 (5'- GAT TCT GGT TCC TCA AGT GTT ATC TTG-3') and NAP219 (5'-CAA GAT AAC ACT TGA GGA ACC AGA ATC-3') for CaPCNA; and NAP284 (5'-CGG TGA CAT CGG ATC ATC ATC AGT CAT AAT AAA ACC-3') and

Table 1 Strains used in this study

\begin{tabular}{|c|c|c|}
\hline Strain & Genotype & Source/ Reference \\
\hline SC5314 & C. albicans Wild type & [25] \\
\hline EMY74.7 & MATa, his3- $\Delta 1$, leu2-3, leu2-112, trp1 $\Delta$, ura3-52 & {$[32]$} \\
\hline \multirow[t]{3}{*}{ HFY7C } & MATa, ura3-52, his3-200, ade2-101, lys2-80,1 trp1-901, & \\
\hline & leu2-3,112 gal4-542, gal80-538, LYS2::GAL1-HIS3 & Clontech \\
\hline & URA3:::(GAL4 17mer) ${ }_{3}-C Y C 1$ lacZ & \\
\hline YTS9 & $\begin{array}{l}\text { MATa ura3-52 trp1D901 leu2-3,112 can1 pol3041, with pBL230-6 } \\
\text { (YCP50, TRP1, POL30 with DD41,42AA) }\end{array}$ & Ayyagari etal \\
\hline YNA01 & YTS9 with pNA1005 (2 $\mu$, ADH1p,URA3) & This study \\
\hline YNA03 & YTS9 with pNA1006 (2 $\mu$, ADH1p-CaPCNA,URA3) & This study \\
\hline YNA05 & 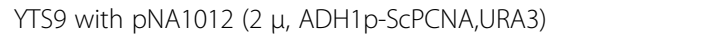 & This study \\
\hline YNA07 & YTS9 with pNA1005(2 $\mu$, ADH1 p-Ca PCNA G178S,URA3) & This study \\
\hline YNA09 & MATa ura3-52 trp1D901 leu2-3,112 can1 pol3041, pNA1006 & This study \\
\hline YNA11 & MATa ura3-52 trp1D901 leu2-3,112 can1 pol3041, pNA1012 & This study \\
\hline YNA13 & YTS9 with pNA901(2 $\mu$, CaPCNA gene,URA3) & This study \\
\hline YNA15 & YTS9 with pNA903(2 $\mu$,CaPCNA gene G178S,URA3) & This study \\
\hline YNA21 & YTS9 with YCplac33 & This study \\
\hline YNA23 & YTS9 with pNA983(CEN, CaPCNAgene, URA3) & This study \\
\hline YNA25 & YTS9 with pNA984(CEN,URA3,CaPCNAgene G178S) & This study \\
\hline YNA27 & YNA11 with YEp lac181 & This study \\
\hline YNA29 & YNA11 with pNA1186 (2 $\mu$, ADH1p-Ca PCNA, LEU) & This study \\
\hline YNA31 & YNA11 with pNA1188 (2 $\mu$, ADH1p-Ca PCNA G178S, LEU) & This study \\
\hline YNA33 & YNA11 with pNA1194 (2 $\mu$, CaPCNA gene LEU) & This study \\
\hline YNA35 & 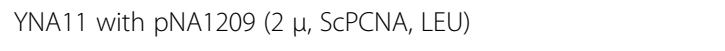 & This study \\
\hline YNA41 & MATa ura3-52 trp1D901 leu2-3,112 can1 pol3041, pNA901 & This study \\
\hline YNA43 & MATa ura3-52 trp1D901 leu2-3,112 can1 pol3041, pNA983 & This study \\
\hline YNA45 & YNA11 with pNA1209 (2 $\mu$, SCPCNA G178S, LEU) & This study \\
\hline
\end{tabular}


NAP285 (5'-GGT TTT ATT ATG ACT GAT GAT GAT CCG ATG TCA CCG-3') for ScPCNA, respectively. PCR conditions included 1 cycle of $95^{\circ} \mathrm{C}$ for $3 \mathrm{~min}, 20$ cycles of $95{ }^{\circ} \mathrm{C}$ for $1 \mathrm{~min}, 50{ }^{\circ} \mathrm{C}$ for $30 \mathrm{~s}$, and $68{ }^{\circ} \mathrm{C}$ for $3.5 \mathrm{~min}$, and finally 1 cycle of $68{ }^{\circ} \mathrm{C}$ for $10 \mathrm{~min}$. The PCR product was treated with DpnI (NEB) overnight and transformed into E.coli TG1 competent cells. The colonies were screened by sequencing.

\section{Purification of recombinant proteins}

The expression of PCNA proteins were carried out in $E$. coli BL21-DE3 strain. The proteins were expressed as glutathione S-transferase fusion proteins under T7 promoter by using a protocol described previously [46, 48]. Briefly, $10 \mathrm{ml}$ preculture was inoculated into $1 \mathrm{lt} \mathrm{LB}+$ $100 \mu \mathrm{g} / \mathrm{ml}$ ampicillin and grown at $37^{\circ} \mathrm{C}$ to an $\mathrm{OD}_{600}$ of 0.6. Further the culture was induced by adding $1 \mathrm{mM}$ IPTG, and incubated for an additional 6 to $8 \mathrm{~h}$. About $5 \mathrm{gm}$ of cell pellet was resuspended in $20 \mathrm{ml}$ cell breaking buffer (50 mM Tris- $\mathrm{HCl} \mathrm{pH} \mathrm{7.5,} 10 \%$ sucrose, 1 mM EDTA and $500 \mathrm{mM} \mathrm{NaCl}$ ) containing a 1:200 dilution of the protease inhibitor mixture, suspension was pressure lysed using a French press at $20,000 \mathrm{psi}$ at $4{ }^{\circ} \mathrm{C}$. The lysate was clarified by centrifugation at 10,000 RPM for $10 \mathrm{~min}$, and further at 20,000 RPM for $1 \mathrm{~h}$. The clear supernatant was passed twice through GST beads (GE-healthcare) packed in $10 \mathrm{ml}$ plastic column. Protein bound beads were first thoroughly washed using the above mentioned buffer with $1 \mathrm{M} \mathrm{NaCl}$, and then with equilibration buffer (50 mM Tris- $\mathrm{HCl}$ pH 7.5, $150 \mathrm{mM} \mathrm{NaCl}, 10 \%$ glycerol, $5 \mathrm{mM}$ DTT and $0.01 \% \mathrm{NP}-40$ ). The protein was eluted from the beads after overnight incubation with Prescission protease (GE-Healthcare) that cleaves PCNA from GST. Purified proteins were estimated by both Bradford's and gel based assay using bovine serum albumin as a standard. Proteins were analyzed by electrophoresis on $12 \%$ polyacrylamide gels without or containing either $0.1 \%$ SDS or 2-6 M urea [49], and visualized by Coomassie Brilliant Blue R-250 staining .

ScPoln was also purified by above mentioned protocol except that GAL-PGK-GST-ScRAD30 construct was expressed in YRP654 protease deficient yeast strain [48].

\section{Glutaraldehyde cross-linking}

About $20 \mu \mathrm{g}$ of native or mutant PCNA in $20 \mathrm{mM}$ HEPES buffer ( $\mathrm{pH} 7.5$ ) was mixed with $1 \mu \mathrm{l}$ of $8 \%$ freshly prepared glutaraldehyde solution for $5 \mathrm{~min}$ at $37{ }^{\circ} \mathrm{C}$. The reaction was terminated by adding equal volume of $1 \mathrm{M}$ Tris- $\mathrm{HCl}$ ( $\mathrm{pH}$ 8.0). Cross-linked protein was solubilized with sample buffer and electrophoresis was conducted on $12 \%$ SDS-PAGE.

\section{Size exclusion chromatography}

For size exclusion chromatography, about $10 \mu \mathrm{g}$ of purified proteins were loaded onto a Superdex 200 PC3.2/30 column pre-equilibrated with buffer containing $50 \mathrm{mM}$ HEPES pH7.5, $150 \mathrm{mM} \mathrm{NaCl}$ and $10 \%$ glycerol. Chromatography was performed on an AKTApure $M$ system (GE Healthcare) at a flow rate of $0.05 \mathrm{ml} / \mathrm{min}$ at $4{ }^{\circ} \mathrm{C}$, and the absorbance was monitored at $280 \mathrm{~nm}$.

\section{Complementation analysis by plasmid curing}

Plasmids YCplac33 (CEN, URA3) or YEplac195 (2 $\mu$, URA3) harbouring CaPOL30 or CaPOL30 G178S genes, and YEplac195-ScADH1p (2 $\mu$, URA3) expressing CaPol30 or CaPol30 G178S or ScPol30 orfs were transformed into YTS9 strain and the transformants were selected on synthetic media without tryptophan and uracil. For control experiments empty vectors were also transformed. In order to cure the resident plasmid containing mutant ScPOL30 (YCP-ScPOL30 DE41,42AA, TRP1), a transformant from each plate was grown on liquid media omitting uracil at $30{ }^{\circ} \mathrm{C}$ in shaking condition. After every $24 \mathrm{hrs}, 100 \mu \mathrm{l}$ of the culture was diluted with fresh $5 \mathrm{ml}$ of SD w/o uracil media and allowed to grow. After seven such consecutive subculturing, the cultures were streaked on SD w/o uracil plates to obtain isolated colonies. About 30 isolated colonies were patched on both SD agar plates lacing uracil alone or tryptophan alone. Further the plates were incubated at $30{ }^{\circ} \mathrm{C}$ for 2 days and number of colonies appeared on each plates were counted. The lack of growth on SD-tryptophan plate but growth on SD-uracil suggested complete curing of the resident PCNA and complementation due to the incoming plasmid. On the other hand, preservation of both the nutritional markers (URA and TRP) indicated that the tester plasmid is unable to complement for ScPOL30. After curing, the strains were confirmed by PCR for the presence of respective plasmids.

\section{Plasmid segregation by 5-FOA counter selection}

Yeast strain YNA05 is a genomic null for POL30 but harbors YEplac195-ScADH1p-ScPol30 (URA3). An empty YEplac181-ScADH1p (LEU2) or containing CaPol30 or CaPol30 G178S or ScPol30 G178S orfs were transformed into above strain. Candida PCNA with its own promoter in YEplac181 vector was also transformed. The transformants were streaked on SD media w/o leucine and uracil. Isolated colonies were picked and re-streaked on SD-leucine agar plate but with or without $5^{\prime}$-fluoroorotic acid $(10 \mathrm{mg} / \mathrm{ml})$. After counter selection with $5^{\prime}$-FOA, the absence of original PCNA in strains surviving on FOA containing plate was confirmed by PCR. 


\section{Growth rates}

Growth rates for yeast strains were examined by inoculating the required volume of pre-culture to $100 \mathrm{ml}$ fresh YPD liquid medium to get $0.1 \mathrm{O}^{\mathrm{D}} \mathrm{D}_{600}$ at $0 \mathrm{~h}$. About $1 \mathrm{ml}$ culture was taken out in every $1 \mathrm{~h}$ for $18 \mathrm{hrs}$ and the growth rate at $30{ }^{\circ} \mathrm{C}$ was monitored by measuring absorbance at $600 \mathrm{~nm}$. Growth of the strains was also monitored at $14{ }^{\circ} \mathrm{C}$ and $35^{\circ} \mathrm{C}$.

\section{RT-PCR analysis}

Total RNAs were isolated from various yeast stains those were used in estimating growth rates by using MP FastRNA Pro isolation kit (Cat\#6025-050) as per the manufacturer's protocol and then samples were treated with DNAase I enzyme. Equal amount of RNAs were subjected to cDNA synthesis using a reverse transcription core kit from Eurogentec (RTRTCK-03). A $50 \mu \mathrm{l}$ PCR reaction was carried out containing $3 \mu \mathrm{l}$ of synthesized c-DNA, $200 \mu \mathrm{M}$ dNTPs, $1 \times$ Taq DNA polymerase buffer, $1.5 \mathrm{mM}$ $\mathrm{MgCl}_{2}$ and $2 \mathrm{U}$ of Taq DNA polymerase (Sigma) and 20pmol each of the primers NAP31 (5'-GGC CAA GCT TGG ATC CAC ATA TGT TAG AAG GTA AAT TTG AAG -3') and NAP32 (5'- GGC CGA ATT CGG ATC CCT ACT CAT CAT CAT CG-3') for the CaPCNA; and NAP205 (5'- GGC CGG TAC CGG ATC CAT ACA TGT TAG AAG CAA AAT TTG-3') and NAP210 (5'- GGC CAA GCT TGG ATC CTT ATT CTT CGT CAT TAA ATT TAG G-3') for the ScPCNA, respectively. Primers pair NAP297 (5'-GGC CGG ATC CGT ATG TCA AAA TTT ACT TGG -3') and NAP298 (5'-GGC CGG ATC CTC ATT TTT TTC TTG TAA AAA ATG-3') were used for amplification of ScPoln. PCR conditions included initial heating at $95{ }^{\circ} \mathrm{C}$ for 3 ' followed by 25 cycles at $95{ }^{\circ} \mathrm{C}$ for $30 \mathrm{~s}, 52{ }^{\circ} \mathrm{C}$ for $45 \mathrm{~s}, 68^{\circ}$ C for 1' (PCNA) or 1' $45 \mathrm{~s}$ (Poln). PCR products were separated on $1 \%$ agarose gel and image captured on Chemi XRS Gel Documentation System (Bio-Rad). PCR reaction was also repeated with RNA alone as template to rule out any genomic DNA contamination in our preparation. Intensity of each band was calculated by ImageJ software and relative fold change of PCNA vs Poln was estimated.

\section{Sensitivity to different DNA damaging agents}

All the pre-cultures of various strains were diluted to achieve equal number of cells in autoclaved water. Further these strains were 10 folds serially diluted and spotted on YPD plates containing with or without different concentrations of drugs like hydroxyurea (HU), methyl methane sulfonate (MMS), $\mathrm{H}_{2} \mathrm{O}_{2}$ and tert-Butyl hydroperoxide (TBHP). The plates were incubated at $30{ }^{\circ} \mathrm{C}$ for 3 days and then photographed. Uridine $(100 \mu \mathrm{g} / \mathrm{ml})$ was added when required.

\section{Physical interaction by Surface Plasmon Resonance}

Interaction of PCNA with DNA polymerase eta $(\operatorname{Rad} 30 / \eta)$ was monitored using Bio-Rad XPR 36 surface plasmon resonance biosensor instrument. About $5 \mu \mathrm{g}$ of CaPCNA or ScPCNA or BSA ( 350 RU) was immobilized on GLC chip by amine coupling method as suggested by manufacturer's instructions. ScPol $\eta$ was injected at concentration ranging from $25-500 \mathrm{nM}$ with running buffer composed of $25 \mathrm{mM}$ HEPES pH 7.5, $10 \%$ glycerol, $200 \mathrm{mM}$ Sodium acetate $\mathrm{pH}$ 7.8, 8 mM Magnesium acetate, $1 \mathrm{mM}$ DTT, $0.005 \%$ Tween-20 and $0.2 \mathrm{mg} / \mathrm{ml} \mathrm{BSA}$, at a flow rate of $50 \mu \mathrm{l} / \mathrm{min}$ for $180 \mathrm{~s}$ with a $600 \mathrm{~s}$ dissociation phase. Molecular interaction was carried out at $20{ }^{\circ} \mathrm{C}$. Further the dissociation constants were determined, after fitting the association and dissociation curves to a 1:1 (Langmuir)-binding model.

\section{Bioinformatics analysis of Candida PCNA}

The BLAST server from the NCBI was used to search for similarities between Candida PCNA protein and sequences deposited in the Protein Databank (PDB). Based on the structures of homologues proteins, CaPCNA was modelled using SWISS MODEL (http:// swissmodel.expasy.org/) [50], an automated protein modelling Server. Saccharomyces cerevisiae PCNA PDB structures with ID 2OD8 and 1PLR were used as template for monomeric and trimeric PCNA, respectively. Stereochemical quality of the model structured of CaPCNA was further analysed by the metaserver SAVES. The Ramachandran plot was derived by PROCHECK and secondary structure prediction of CaPCNA was performed with PSIPRED v3.3 softwares $[51,52]$.

\section{Additional files}

Additional file 1: Table S1. Average O.D. ${ }_{600}$ of three sets of experiments (XLSX $11 \mathrm{~kb}$ )

Additional file 2: Table S2. Quantification of band intensities of Semi-quantitative RT PCR for yeast expressing various PCNAs (XLSX $11 \mathrm{~kb})$

\begin{abstract}
Abbreviations
PCNA: Proliferating Cell Nuclear Antigen; IDCL: Inter Domain Connecting Loop; RFC: Replication factor C; MMR: Mismatch Repair; NHEJ: Non-homologous End Joining; ADH: Alcohol Dehydrogenase; 5-FOA: 5-Fluoroorotic Acid; GST: Glutathione S-trasferase; BSA: Bovine Serum Albumin; RU: Response Unit; RMSD: Root mean square deviation; Poln: DNA polymerase eta; HU: Hydroxyurea; UV: Ultra Violet; MMS: Methyl Methanesulfonate; $\mathrm{H}_{2} \mathrm{O}_{2}$ : Hydrogen Peroxide; TBHP: tert-Butyl Hydroperoxide; CEN: Centromere; ROS: Reactive Oxygen Species; RNI: Reactive Nitrogen Intermediates.
\end{abstract}

\section{Competing interests}

We declare no competing interests.

\section{Authors' contributions}

KM designed, conducted the experiments, helped in analyzing and drafting the manuscript. NA participated in the study design, analyzed the results and 
drafted the manuscript. All the authors have read and approved the final manuscript.

\section{Acknowledgement}

We thank Prof. Louise and Satya Prakash for providing precursor plasmids and strains for our research. We also thank Prof. A. P. Mitchell for C. albicans strain, Mr. Sitendra Panda for his scientific assistance, Ms. Amrita Dalei for ScPoln protein and XPR experiment, and our laboratory colleagues for helpful discussion. This work was generously supported by the intramural core grant provided by Director, ILS.

\section{Received: 3 June 2015 Accepted: 23 October 2015}

Published online: 04 November 2015

\section{References}

1. Kuriyan J, O'Donnell M. Sliding clamps of DNA polymerases. J Mol Biol. 1993;234(4):915-25.

2. Maga G, Hubscher U. Proliferating cell nuclear antigen (PCNA): a dancer with many partners. J Cell Sci. 2003;116(Pt 15):3051-60.

3. Waga S, Stillman B. The DNA replication fork in eukaryotic cells. Annu Rev Biochem. 1998:67:721-51

4. Moldovan GL, Pfander B, Jentsch S. PCNA, the maestro of the replication fork. Cell. 2007;129(4):665-79.

5. Krishna TS, Fenyo D, Kong XP, Gary S, Chait BT, Burgers P, et al. Crystallization of proliferating cell nuclear antigen (PCNA) from Saccharomyces cerevisiae. J Mol Biol. 1994;241(2):265-8.

6. Krishna TS, Kong XP, Gary S, Burgers PM, Kuriyan J. Crystal structure of the eukaryotic DNA polymerase processivity factor PCNA. Cell. 1994;79(7):1233-43.

7. Pan M, Kelman LM, Kelman Z. The archaeal PCNA proteins. Biochem Soc Trans. 2011;39(1):20-4.

8. Bruck I, O'Donnell M. The ring-type polymerase sliding clamp family. Genome Biol. 2001:2(1):3001.

9. Yao NY, Johnson A, Bowman GD, Kuriyan J, O'Donnell M. Mechanism of proliferating cell nuclear antigen clamp opening by replication factor C. J Biol Chem. 2006;281(25):17528-39.

10. Gulbis JM, Kelman Z, Hurwitz J, O'Donnell M, Kuriyan J. Structure of the C-terminal region of p21(WAF1/CIP1) complexed with human PCNA. Cell. 1996:87(2):297-306.

11. Burgess RC, Sebesta M, Sisakova A, Marini VP, Lisby M, Damborsky J, et al. The PCNA interaction protein box sequence in Rad54 is an integral part of its ATPase domain and is required for efficient DNA repair and recombination. PLoS One. 2013;8(12):e82630

12. Acharya $\mathrm{N}$, Klassen $\mathrm{R}$, Johnson RE, Prakash $\mathrm{L}$, Prakash S. PCNA binding domains in all three subunits of yeast DNA polymerase delta modulate its function in DNA replication. Proc Natl Acad Sci U S A. 2011;108(44):17927-32.

13. Loor G, Zhang SJ, Zhang P, Toomey NL, Lee MY. Identification of DNA replication and cell cycle proteins that interact with PCNA. Nucleic Acids Res. 1997;25(24):5041-6.

14. Masih PJ, Kunnev D, Melendy T. Mismatch Repair proteins are recruited to replicating DNA through interaction with Proliferating Cell Nuclear Antigen (PCNA). Nucleic Acids Res. 2008;36(1):67-75.

15. Vijayakumar S, Chapados BR, Schmidt KH, Kolodner RD, Tainer JA, Tomkinson AE The C-terminal domain of yeast PCNA is required for physical and functional interactions with Cdc9 DNA ligase. Nucleic Acids Res. 2007;35(5):1624-37.

16. Haracska L, Kondratick CM, Unk I, Prakash S, Prakash L. Interaction with PCNA is essential for yeast DNA polymerase eta function. Mol Cell. 2001;8(2):407-15

17. Eissenberg JC, Ayyagari R, Gomes XV, Burgers PM. Mutations in yeast proliferating cell nuclear antigen define distinct sites for interaction with DNA polymerase delta and DNA polymerase epsilon. Mol Cell Biol. 1997;17(11):6367-78.

18. Ayyagari R, Impellizzeri KJ, Yoder BL, Gary SL, Burgers PM. A mutational analysis of the yeast proliferating cell nuclear antigen indicates distinct roles in DNA replication and DNA repair. Mol Cell Biol. 1995;15(8):4420-9.

19. Lau PJ, Flores-Rozas H, Kolodner RD. Isolation and characterization of new proliferating cell nuclear antigen (POL30) mutator mutants that are defective in DNA mismatch repair. Mol Cell Biol. 2002:22(19):6669-80.

20. Warbrick E, Heatherington W, Lane DP, Glover DM. PCNA binding proteins in Drosophila melanogaster : the analysis of a conserved PCNA binding domain. Nucleic Acids Res. 1998;26(17):3925-32.
21. Waseem NH, Labib K, Nurse $P$, Lane DP. Isolation and analysis of the fission yeast gene encoding polymerase delta accessory protein PCNA. EMBO J. 1992;11(13):5111-20

22. Niimi A, Suka N, Harata M, Kikuchi A, Mizuno S. Co-localization of chicken DNA topoisomerase Ilalpha, but not beta, with sites of DNA replication and possible involvement of a C-terminal region of alpha through its binding to PCNA. Chromosoma. 2001;110(2):102-14.

23. Guo C, Sonoda E, Tang TS, Parker JL, Bielen AB, Takeda S, et al. REV1 protein interacts with PCNA: significance of the REV1 BRCT domain in vitro and in vivo. Mol Cell. 2006;23(2):265-71.

24. Raynaud C, Sozzani R, Glab N, Domenichini S, Perennes C, Cella R, et al. Two cell-cycle regulated SET-domain proteins interact with proliferating cell nuclear antigen (PCNA) in Arabidopsis. Plant J. 2006;47(3):395-407.

25. Kaufmann D, Gassen A, Maiser A, Leonhardt H, Janzen CJ. Regulation and spatial organization of PCNA in Trypanosoma brucei. Biochem Biophys Res Commun. 2012;419(4):698-702.

26. Berman J. Candida albicans. Current Biol. 2012;22(16):R620-2.

27. Calderone R, Odds FC, Boekhout T. Candida albicans: fundamental research on an opportunistic human pathogen. FEMS Yeast Res. 2009;9(7):971-2.

28. Mitchell AP. Dimorphism and virulence in Candida albicans. Curr Opin Microbiol. 1998;1(6):687-92.

29. Legrand $M$, Chan $C L$, Jauert PA, Kirkpatrick DT. Analysis of base excision and nucleotide excision repair in Candida albicans. Microbiology. 2008;154(Pt 8):2446-56.

30. Legrand $\mathrm{M}$, Chan $\mathrm{CL}$, Jauert PA, Kirkpatrick DT. Role of DNA mismatch repair and double-strand break repair in genome stability and antifungal drug resistance in Candida albicans. Eukaryot Cell. 2007;6(12):2194-205.

31. Ulrich HD, Takahashi T. Readers of PCNA modifications. Chromosoma. 2013;122(4):259-74.

32. Zhang H, Gibbs PE, Lawrence CW. The Saccharomyces cerevisiae rev6mutation, which inhibits both the lesion bypass and the recombination mode of DNA damage tolerance, is an allele of POL30, encoding proliferating cell nuclear antigen. Genetics. 2006;173(4):1983-9.

33. Dieckman LM, Washington MT. PCNA trimer instability inhibits translesion synthesis by DNA polymerase eta and by DNA polymerase delta. DNA Repair. 2013;12(5):367-76.

34. Naryzhny SN, Zhao H, Lee H. Proliferating cell nuclear antigen (PCNA) may function as a double homotrimer complex in the mammalian cell. J Biol Chem. 2005;280(14):13888-94

35. Prakash S, Johnson RE, Prakash L. Eukaryotic translesion synthesis DNA polymerases: specificity of structure and function. Annu Rev Biochem. 2005;74:317-53

36. Vazquez-Torres A, Balish E. Macrophages in resistance to candidiasis. Microbio Mol Biol Rev. 1997;61(2):170-92.

37. Braun BR, van Het Hoog M, d'Enfert C, Martchenko M, Dungan J, Kuo A, et al. A human-curated annotation of the Candida albicans genome. PLoS Genet. 2005;1(1):36-57.

38. Xu D, Jiang B, Ketela T, Lemieux S, Veillette K, Martel N, et al. Genome-wide fitness test and mechanism-of-action studies of inhibitory compounds in Candida albicans. PLoS Pathog. 2007;3(6):e92.

39. Cote $\mathrm{P}$, Hogues $H$, Whiteway M. Transcriptional analysis of the Candida albicans cell cycle. Mol Biol Cell. 2009;20(14):3363-73.

40. Kusch $\mathrm{H}$, Engelmann S, Bode R, Albrecht D, Morschhauser J, Hecker M. A proteomic view of Candida albicans yeast cell metabolism in exponential and stationary growth phases. Int J Med Microbiol. 2008;298(3-4):291-318.

41. Liu TT, Lee RE, Barker KS, Lee RE, Wei L, Homayouni R, et al. Genome-wide expression profiling of the response to azole, polyene, echinocandin, and pyrimidine antifungal agents in Candida albicans. Antimicrob Agents Chemother. 2005;49(6):2226-36

42. Chen H, Fujita M, Feng Q, Clardy J, Fink GR. Tyrosol is a quorum-sensing molecule in Candida albicans. Proc Natl Acad Sci U S A. 2004;101(14):5048-52.

43. Ng L, Prelich G, Anderson CW, Stillman B, Fisher PA. Drosophila proliferating cell nuclear antigen. Structural and functional homology with its mammalian counterpart. J Biol Chem. 1990:265(20):11948-54.

44. Zamir L, Zaretsky M, Fridman Y, Ner-Gaon H, Rubin E, Aharoni A. Tight coevolution of proliferating cell nuclear antigen (PCNA)-partner interaction networks in fungi leads to interspecies network incompatibility. Proc Nat Acad Sci U S A. 2012;109(7):E406-14.

45. Xue C, Liang K, Liu Z, Wen R, Xiao W. Similarities and differences between Arabidopsis PCNA1 and PCNA2 in complementing the yeast DNA damage tolerance defect. DNA Repair. 2015;28:28-36. 
46. Acharya N, Brahma A, Haracska L, Prakash L, Prakash S. Mutations in the ubiquitin binding UBZ motif of DNA polymerase eta do not impair its function in translesion synthesis during replication. Mol Cell Biol. 2007;27(20):7266-72.

47. Santos MA, Tuite MF. The CUG codon is decoded in vivo as serine and not leucine in Candida albicans. Nucleic Acids Res. 1995:23(9):1481-6.

48. Johnson RE, Prakash L, Prakash S. Yeast and human translesion DNA synthesis polymerases: expression, purification, and biochemical characterization. Methods Enzymol. 2006;408:390-407.

49. Acharya N, Roy S, Varshney U. Mutational analysis of the uracil DNA glycosylase inhibitor protein and its interaction with Escherichia coli uracil DNA glycosylase. J Mol Biol. 2002;321(4):579-90.

50. Arnold K, Bordoli L, Kopp J, Schwede T. The SWISS-MODEL workspace: a web-based environment for protein structure homology modelling. Bioinformatics. 2006;22(2):195-201.

51. Jones DT. Protein secondary structure prediction based on position-specific scoring matrices. J Mol Biol. 1999:292(2):195-202.

52. Morris AL, MacArthur MW, Hutchinson EG, Thornton JM. Stereochemical quality of protein structure coordinates. Proteins. 1992;12(4):345-64.

\section{Submit your next manuscript to BioMed Central and take full advantage of:}

- Convenient online submission

- Thorough peer review

- No space constraints or color figure charges

- Immediate publication on acceptance

- Inclusion in PubMed, CAS, Scopus and Google Scholar

- Research which is freely available for redistribution 